\title{
Single-Dose Euglycemic Clamp Study Demonstrating Pharmacokinetic and Pharmacodynamic Similarity Between SAR341402 Insulin Aspart and US- and EU-Approved Versions of Insulin Aspart in Subjects with Type 1 Diabetes
}

\author{
Christoph Kapitza, MD, Leszek Nosek, MD, Wolfgang Schmider, $\mathrm{PhD}^{2}$ \\ Lenore Teichert, $\mathrm{MSc}^{2}$ and Irene Nowotny, $\mathrm{PhD}^{2}$
}

\begin{abstract}
Background: The objective of this study was to demonstrate the pharmacokinetic and pharmacodynamic similarity among SAR341402 insulin aspart biosimilar/follow-on product, United States-sourced insulin aspart $\left(\right.$ NovoLog $\left.^{\circledR}\right)$, and European Union-sourced insulin aspart (NovoRapid $\left.{ }^{\circledR}\right)$.

Materials and Methods: This was a single-center, randomized, double-blind, 3-treatment, 3-period, single-dose, crossover euglycemic study (NCT03202875) in 30 adult male subjects with type 1 diabetes (T1D). Subjects received $0.3 \mathrm{U} / \mathrm{kg}$ of each treatment under fasted conditions and underwent a 12 -h euglycemic clamp technique to assess pharmacokinetic and pharmacodynamic activity for up to $12 \mathrm{~h}$. Primary endpoints were area under the plasma insulin concentration-time curve from time zero to the last quantifiable concentration (INS-AUC last $_{\text {) }}$, and extrapolated to infinity (INS- $\mathrm{AUC}_{\mathrm{inf}}$ ), maximum plasma insulin concentration (INS- $\mathrm{C}_{\max }$ ), and the area under the body weight-standardized glucose infusion rate (GIR)-time curve from 0 to 12 hours (GIR-AUC ${ }_{0-12 h}$ ) among the three treatments. GIR $\mathrm{max}_{\max }$ was the main secondary endpoint.

Results: Of the 30 subjects randomized, 29 completed all 3 treatment periods. Pharmacokinetic and pharmacodynamic profiles were similar in all groups. The extent of exposure (INS- $\mathrm{C}_{\max }$, INS-AUC last $_{\text {, and INS- }}$ $\left.\mathrm{AUC}_{\mathrm{inf}}\right)$ and glucodynamic activity (GIR-AUC $\left.{ }_{0-12 \mathrm{~h}}, \mathrm{GIR}_{\max }\right)$ was similar among the three treatments. The corresponding $90 \%$ confidence intervals for pairwise treatment ratios were completely contained within the limits of $80 \%-125 \%$. SAR341402 was well tolerated.

Conclusions: The present study demonstrated similar pharmacokinetic exposure profiles and glucodynamic potency among SAR341402, NovoLog, and NovoRapid in subjects with T1D, supporting further clinical evaluation of SAR341402 as a biosimilar/follow-on product.
\end{abstract}

Keywords: Insulin aspart, Biosimilar, Pharmacodynamics, Pharmacokinetics, Phase I study, Type 1 diabetes.

Introduction

TNSULIN ASPART IS a rapid-acting human insulin analog

of recombinant DNA origin. It is the active ingredient of the currently approved marketed products $\operatorname{NovoLog}^{\circledR}$ and NovoLog Mix in the United States (US), ${ }^{1}$ and NovoRapid ${ }^{\circledR}$ and NovoMix ${ }^{\circledR}$ in the European Union (EU) ${ }^{2}$ for the treatment of hyperglycemia. It has been widely used in clinical

\footnotetext{
${ }^{1}$ Profil Institut für Stoffwechselforschung GmbH, Neuss, Germany.

${ }^{2}$ Sanofi-Aventis Deutschland GmbH, Frankfurt, Germany.

Prior presentation: Preliminary results were previously published as an abstract and presented as a poster at the 79th Scientific Sessions of the American Diabetes Association, June 7-11, 2019, San Francisco, California (Abstract 130-LB).

(C) Christoph Kapitza, et al., 2019; Published by Mary Ann Liebert, Inc. This Open Access article is distributed under the terms of the Creative Commons Attribution Noncommercial License (http://creativecommons.org/licenses/by-nc/4.0/) which permits any noncommercial use, distribution, and reproduction in any medium, provided the original author(s) and the source are credited.
} 
practice for about 20 years, with a well-characterized pharmacological efficacy and safety profile. ${ }^{3}$

Rising insulin costs remain a concern for people with diabetes, their families, and health care providers. ${ }^{4}$ The development of new biosimilar or follow-on insulin products over the last few years, including rapid-acting insulins, has the potential to reduce drug treatment costs and thereby facilitate greater access of insulin treatment for people with diabetes. ${ }^{5}$ In July 2017, the first rapid-acting insulin biosimilar/follow-on product (SAR342434, insulin lispro Sanofi) was approved in Europe and subsequently in other countries for the same indications as the reference drug. ${ }^{6,7}$ SAR341402 insulin aspart solution for injection (SAR-Asp; Sanofi, Paris, France) is the second rapid-acting insulin biosimilar/followon product to undergo evaluation, having the same amino acid sequence and corresponding structure as insulin aspart in the reference medicinal product, NovoLog (NN-Asp-US)/ NovoRapid (NN-Asp-EU). SAR-Asp is produced in Escherichia coli, while NN-Asp-US/NN-Asp-EU is produced in Saccharomyces cerevisiae or baker's yeast. Consistent with regulatory guidance, the development of SAR-Asp is based on establishing a biological medicinal product that is similar to the already authorized original biological medicinal product in terms of quality, safety, and efficacy, based on a comprehensive comparability exercise. ${ }^{8}$

SAR-Asp has been developed as a similar biological medicinal product to NN-Asp-US/NN-Asp-EU (100 U/mL) in accordance with relevant US and EU guidelines. ${ }^{8-11}$ SARAsp was shown to be similar to NN-Asp-US/NN-Asp-EU through physicochemical analysis and nonclinical studies, including in vitro and in vivo analyzes. It is intended to have the same indications, dosage form, routes of administration and dosing regimen as NN-Asp-US/NN-Asp-EU. The clinical development program of SAR-Asp was designed to demonstrate similarity in the pharmacokinetic and pharmacodynamic profiles, efficacy, and safety (including immunogenicity) between SAR-Asp and NN-Asp-US/NN-Asp-EU.

In this study, we report the results of a study to demonstrate similarity in pharmacokinetic exposure and glucodynamic activity of the SAR-Asp insulin aspart product to NN-AspUS and NN-Asp-EU using the euglycemic clamp technique in subjects with type 1 diabetes (T1D).

\section{Materials and Methods}

This was a single-center, randomized, double-blind, controlled, single-dose, 3-treatment, 3-period, 6-sequence, euglycemic clamp crossover study (ClinicalTrials.gov identifier: NCT03202875) undertaken in 2012. The study protocol was approved by an independent Ethics Committee and conducted in accordance with the Declaration of Helsinki. Written informed consent was obtained from all subjects before study entry.

\section{Subjects}

Participants were enrolled at the Profil Institute (Neuss, Germany) and included subjects aged 18-65 years with T1D (duration $>1$ year) but otherwise healthy, with a body mass index of 18 to $30 \mathrm{~kg} / \mathrm{m}^{2}$, a fasting negative serum C-peptide level $<0.3 \mathrm{nmol} / \mathrm{L}$, a glycated hemoglobin level $\leq 75 \mathrm{mmol} /-$ mol $(\leq 9 \%)$, a total insulin dose of $<1.2 \mathrm{U} /(\mathrm{kg} \cdot$ day), and a stable insulin regimen for at least 2 months before the study.

\section{Study design and treatments}

The study comprised a screening period followed by three treatment periods, each separated by a 5 to 18 -day washout period (Supplementary Fig. S1). Subjects were randomly assigned using a computer-generated list to receive one of six possible treatment sequences for single $0.3 \mathrm{U} / \mathrm{kg}$ doses of SARAsp (test product), NN-Asp-US (insulin aspart $100 \mathrm{U} / \mathrm{mL}$ ), or NN-Asp-EU (100 U/mL insulin aspart). SAR-Asp was manufactured by Sanofi (Frankfurt, Germany) and provided as solution for injection at a concentration of $100 \mathrm{U} / \mathrm{mL}$. NNAsp-US and NN-Asp-EU were provided as commercial formulations. To maintain double-blinding and consistency of dosing methodology, study treatments were withdrawn by an unblinded investigator from cartridges with insulin syringes; this person was not otherwise involved in the study.

\section{Pharmacokinetic evaluation}

Venous blood samples were collected before and then at frequent times after dosing in each treatment period; that is, every $10 \mathrm{~min}$ for the first $2 \mathrm{~h}$, every $15 \mathrm{~min}$ from 2 to $4 \mathrm{~h}$, every $20 \mathrm{~min}$ from 4 to $6 \mathrm{~h}$, every $30 \mathrm{~min}$ from 6 to $8 \mathrm{~h}$, and then every $60 \mathrm{~min}$ up to $12 \mathrm{~h}$. All samples were centrifuged within 20 min of collection. Plasma was transferred to separate tubes, frozen immediately, and stored at $-60^{\circ} \mathrm{C}$ to $-80^{\circ} \mathrm{C}$ until analysis.

Plasma concentrations of SAR-Asp and NN-Asp-US/ NN-Asp-EU were analyzed using a validated liquid chromatography-tandem mass spectrometry assay at Syneos Health (Québec, Canada). The measurement range of the assay was $100-8000 \mathrm{pg} / \mathrm{mL}$ with $100 \mathrm{pg} / \mathrm{mL}$ defined as the lower limit of quantification. Cross-validation of the assay with NN-Asp-US and NN-Asp-EU was also performed, with the assay shown to be precise, accurate, sensitive, and selective over the validated range. For patients receiving a rescue insulin during the clamp procedure (after dosing of study drugs), plasma concentrations of SAR-Asp and NNAsp-US/NN-Asp-EU were analyzed up to the start time of the rescue insulin administration.

\section{Pharmacodynamic evaluation using euglycemic clamp}

The pharmacodynamic effect of insulin aspart was evaluated using the euglycemic clamp technique, as described previously. ${ }^{12}$ During the euglycemic clamp, the blood glucose (BG) concentration and the glucose infusion rate (GIR), representing the amount of external glucose needed to keep a subject's BG concentration at its target level, were continuously measured and recorded by the clamp device (Biostator, Life Sciences Instruments, Elkhart, IN). The amount of glucose required (area under the body weight-standardized GIR time curve [GIR-AUC]) is a measure of the metabolic activity of the investigated insulin (decrease in endogenous glucose production and variable peripheral glucose uptake). The clamp device determined BG levels in 1 min intervals and adjusted the GIR in response to changes in BG using a predefined algorithm. During the clamp, arterialized venous BG concentration, ${ }^{13}$ which reflects the supply for total glucose utilization of all tissues, and GIRs were continuously monitored (at a rate of $2 \mathrm{~mL} / \mathrm{h}$ ). In addition, blood samples were collected in $30 \mathrm{~min}$ intervals for concurrent calibration 
of the clamp device, which was required for the calibration procedure to maintain the glycemic clamp.

Before receiving study medication, subjects underwent a washout of their usual insulin therapy, with the last dose of basal insulin received at least $48 \mathrm{~h}$ before dosing. Subjects were required to abstain from injection or infusion of shortacting insulin products (other than insulin aspart) for a minimum of $8 \mathrm{~h}$ before dosing (See Supplementary Fig. S2 for further details). The clamp procedure was performed under fasting conditions following an overnight fasting period. Once connected to the clamp device, a variable basal intravenous infusion of insulin glulisine $(0.3 \mathrm{U} / \mathrm{mL})$ or $20 \%$ glucose solution was initiated to achieve a BG target level of $100 \mathrm{mg} / \mathrm{dL}$ [5.5 mmol/L]). After BG levels were stabilized for at least $1 \mathrm{~h}$ without any glucose infusion, the insulin aspart products were administered. The insulin glulisine infusion was discontinued at least $10 \mathrm{~min}$ before dosing. The short action time of insulin aspart after subcutaneous administration meant that monitoring under clamp conditions was limited to $12 \mathrm{~h}$ after study drug injection. This duration was deemed sufficient, allowing for individual variations in insulin elimination and the duration of pharmacodynamic activity. The clamp was prematurely terminated if BG consistently exceeded $200 \mathrm{mg} / \mathrm{dL}(11.1 \mathrm{mmol} / \mathrm{L})$ with no glucose infusion for the last $30 \mathrm{~min}$.

\section{Safety evaluation}

The safety and tolerability of SAR-Asp was assessed by 12-lead electrocardiogram, vital signs, routine laboratory assessments, physical examination, adverse event (AE) reporting, and assessment of injection site reaction. AEs were coded using Medical Dictionary for Regulatory Activities (MedDRA) version 15.1.

\section{Pharmacokinetic and pharmacodynamic parameters}

Pharmacokinetic parameter estimates for SAR-Asp and NN-Asp-US/NN-Asp-EU were calculated using standard noncompartmental methods with Phoenix WinNonlin ${ }^{\circledR}$ version 5.2.1 and PKDMS version 2.2 (Pharsight Corporation, Cary, NC). Area under the plasma insulin aspart concentrationtime curve was calculated using the log-linear trapezoidal rule from time zero (predose) up to the time of the last quantifiable concentration (INS-AUC ${ }_{\text {last }}$ ) and extrapolated to infinity (INS$\mathrm{AUC}_{\mathrm{inf}}$ ). The primary pharmacokinetic endpoints of the study were maximum observed plasma insulin aspart concentration $\left(\mathrm{INS}-\mathrm{C}_{\max }\right)$, INS-AUC $\mathrm{Cast}_{\text {, }}$, and INS-AUC inf $_{\text {- }}$

For derivation of the pharmacodynamic parameters, the individual maximum smoothed body weight standardized GIR ( GIR $_{\max }$ ) was based on smoothed (locally weighted regression in smoothing scatter [LOESS] plots; SAS ${ }^{\circledR}$, PROC LOESS, factor 0.06) body weight standardized GIR data to reduce the noise associated with GIR adjustment. GIR-AUC from 0 to 12 hours $\left(\mathrm{GIR}-\mathrm{AUC}_{0-12 \mathrm{~h}}\right.$ ) was the primary pharmacodynamic endpoint; GIR $_{\max }$ was a secondary endpoint.

\section{Sample size and statistical analyses}

The aim of the study was to demonstrate similarity in exposure and activity of SAR-Asp insulin aspart to NN-Asp-US and NN-Asp-EU. To demonstrate equivalence in pharmacokinetic exposure and pharmacodynamic activity among
SAR-Asp, NN-Asp-US, and NN-Asp-EU, a total of 18 and 24 evaluable subjects, respectively, was required, assuming a true within-subject standard deviation of 0.175 for INS$\mathrm{AUC}_{\text {inf }}$ and 0.20 for GIR-AUC ${ }_{0-12 \mathrm{~h}}$, respectively, for a true treatment ratio of 0.95 . Sample sizes were planned to provide at least $90 \%$ power to demonstrate equivalence with $5 \%$ type 1 error for the pharmacokinetic and pharmacodynamic parameters using the 0.80 to 1.25 acceptance range, in agreement with regulatory guidance. ${ }^{8}$ The study planned to recruit 30 subjects.

The log-transformed INS-C $\mathrm{C}_{\max }$, INS-AUC ${ }_{\text {last }}$, INS-AUC $_{\text {inf }}$, and GIR-AUC ${ }_{0-12 \mathrm{~h}}$ were evaluated with a linear mixed effects model, including subject within sequence as a random effect with period, sequence, and treatment as fixed effects. For each parameter, the estimated difference in treatment means along with the $90 \%$ confidence limits was back transformed to estimate the treatment ratio of geometric means and the confidence limits. Similarity for the primary pharmacokinetic parameters INS-AUC inf $_{\text {and } I N S-C_{\max } \text { and }}$ bioequipotency for the primary pharmacodynamic parameter GIR-AUC ${ }_{0-12 \mathrm{~h}}$ was concluded if the $90 \%$ confidence intervals (CIs) of the treatment ratios of the geometric means were entirely within the 0.80 to 1.25 equivalence interval. GIR $\max$ was analyzed using a corresponding statistical model. For GIR AUC $_{0-12 \mathrm{~h}}$ and $\mathrm{GIR}_{\max }, 95 \%$ CIs were also presented. Statistical analyzes were performed using SAS version 9.2 (SAS Institute, Inc., Cary, NC).

Clamp quality was assessed by determining the time span of euglycemia, defined as the time from dosing to the last value of the smoothed BG concentration curve at or below $105 \mathrm{mg} / \mathrm{dL}(5.8 \mathrm{mmol} / \mathrm{L})$; the duration of euglycemia; the individual mean of the BG concentrations; the precision, defined as the individual coefficient of variation $(\mathrm{CV}, \%)$ of BG device measurements during euglycemia; and the control deviation, defined as the mean absolute difference of individual mean BG measurements from the clamp target level, as described previously. ${ }^{14}$

\section{Results}

Thirty male subjects were randomized and treated. One subject discontinued study treatment prematurely due to an administration problem in one treatment period related to backflow of study medication after dosing of NN-Asp-US. This subject was randomized to a treatment sequence of NNAsp-EU/NN-Asp-US/SAR-Asp and was therefore missing from the pharmacokinetic and pharmacodynamic populations for NN-Asp-US and SAR-Asp (29 subjects each) and

\section{Table 1. Baseline Characteristics of the Study} Population (SAFETy Population)

\begin{tabular}{lc}
\hline & All subjects $(\mathrm{n}=30)$ \\
\hline Male, $n(\%)$ & $30(100.0)$ \\
Age (years) & $44.0 \pm 10.7[22-59]$ \\
White race, $n(\%)$ & $30(100.0)$ \\
Body weight & $79.2 \pm 9.7[54.1-94.2]$ \\
Body mass index $\left(\mathrm{kg} / \mathrm{m}^{2}\right)$ & $24.8 \pm 2.1[19.6-28.4]$ \\
Duration of diabetes, years & $23.9 \pm 12.1[6-48]$ \\
HbA1c, $\%$ & $7.59 \pm 0.82[5.5-8.9]$ \\
\hline
\end{tabular}

All average data are mean \pm SD [range] unless stated otherwise. $\mathrm{HbA1c}$, glycated hemoglobin; SD, standard deviation. 

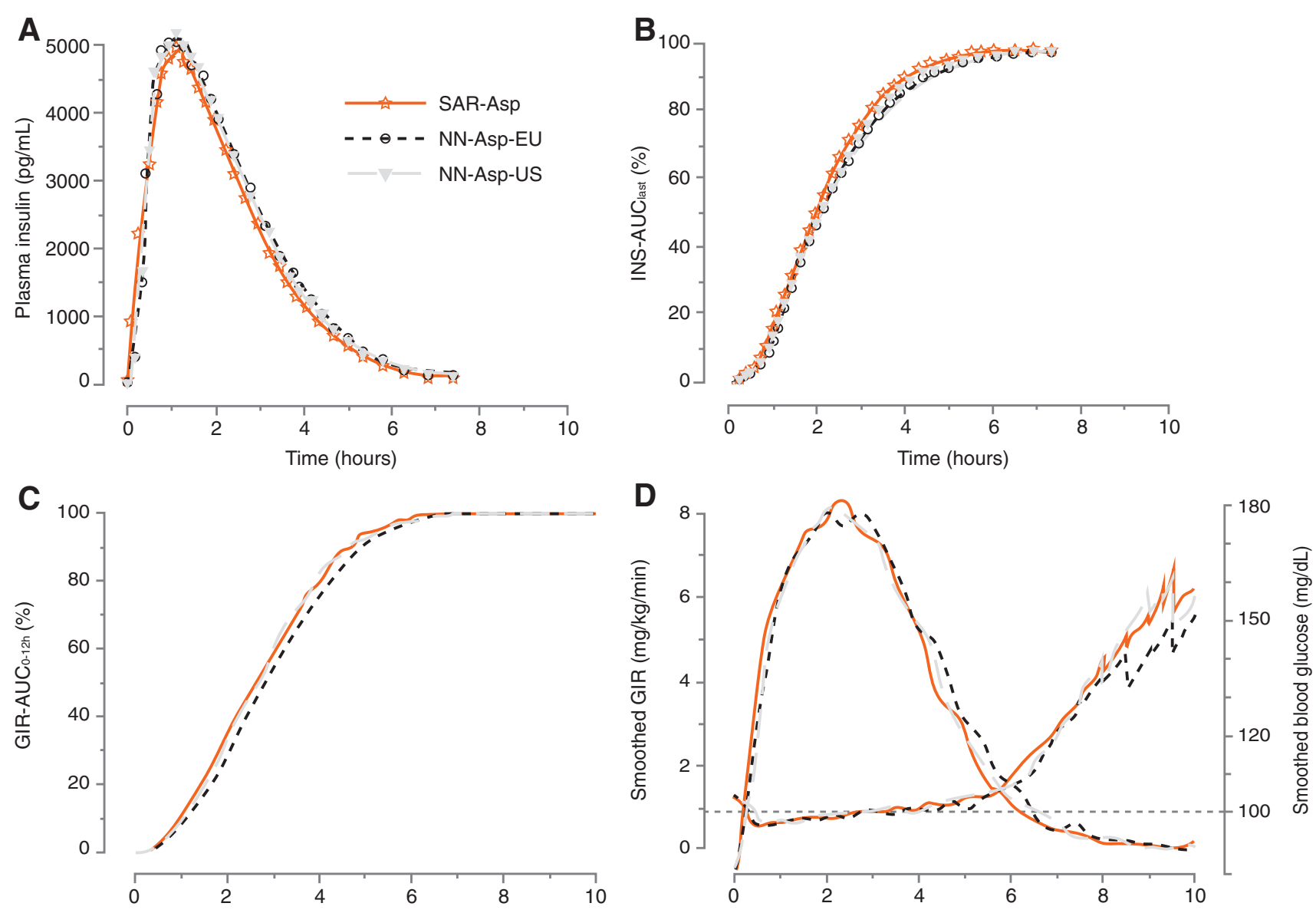

FIG. 1. Pharmacokinetic and pharmacodynamic profiles for SAR-Asp, NN-Asp-US, and NN-Asp-EU versus time. Mean insulin aspart plasma concentration (A), median of percentage of cumulative plasma insulin exposure based on $\mathrm{AUC}_{\text {last }}(\mathbf{B})$, median of percentage cumulative glucose infusion based on GIR-AUC ${ }_{0-12 \mathrm{~h}}(\mathbf{C})$, and mean smoothed body weightstandardized GIR (left curve) and BG profiles (right curve) (D). Values below 0 for the smoothed GIR are mathematical results of the smoothing procedure. The horizontal dotted line in (D) represents the BG target level of $100 \mathrm{mg} / \mathrm{dL}$. BG, blood glucose; GIR, glucose infusion rate; GIR-AUC ${ }_{0-12 \mathrm{~h}}$, area under the body weight-standardized GIR time curve up to 12

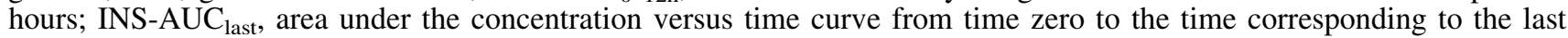
concentration above the limit of quantification.

from the safety population for SAR-Asp. All participants were Caucasian. Baseline characteristics of the subjects are given in Table 1.

\section{Pharmacokinetics}

The pharmacokinetic profiles of the three insulin aspart products were virtually superimposable as shown when plotting the mean insulin aspart concentration versus time (Fig. 1A) and the median of percentage of cumulative insulin aspart concentration (based on $\mathrm{AUC}_{\text {last }}$ ) versus time (Fig. 1B) for SAR-Asp, NN-Asp-US, and NN-Asp-EU. The $90 \%$ CIs of the treatment ratios for INS-C $C_{\max }$, INS-AUC last $_{\text {, }}$, and INS-AUC ${ }_{\text {inf }}$ were entirely within the predefined acceptance interval of 0.80 to 1.25 (Table 2 ), confirming equivalent exposure of the three insulin lispro products. Descriptive statistics per treatment for pharmacokinetic parameters are shown in Supplementary Table S1. The pharmacokinetic parameters show low to moderate between-subject variability, as demonstrated by CVs between $27 \%$ and $37 \%$. Within-subject variability across the three clamps was low,
TABle 2. Pharmacokinetic EndPoints

\begin{tabular}{rlr}
\hline Endpoint & \multicolumn{1}{c}{ Treatment ratio } & $\begin{array}{c}\text { Point } \\
\text { estimate } \\
(90 \% \text { CI })\end{array}$ \\
\hline INS-C $_{\max }$ & SAR-Asp vs. NN-Asp-EU & $0.97(0.90-1.05)$ \\
& SAR-Asp vs. NN-Asp-US & $0.93(0.87-1.01)$ \\
NN-Asp-US vs. NN-Asp-EU & $1.04(0.96-1.12)$ \\
INS-AUC $_{\text {last }}$ & \\
SAR-Asp vs. NN-Asp-EU & $0.93(0.88-0.97)$ \\
SAR-Asp vs. NN-Asp-US & $0.93(0.89-0.98)$ \\
NN-Asp-US vs. NN-Asp-EU & $1.00(0.95-1.05)$ \\
INS-AUC & \\
inf & & \\
SAR-Asp vs. NN-Asp-EU & $0.92(0.88-0.96)$ \\
SAR-Asp vs. NN-Asp-US & $0.92(0.88-0.96)$ \\
NN-Asp-US vs. NN-Asp-EU & $1.00(0.95-1.04)$ \\
\hline
\end{tabular}

CI, confidence interval; INS-AUC ${ }_{\text {last }}$, area under the drug plasma concentration-time curve from time 0 to the time of the last quantifiable data point, INS-AUC ${ }_{\text {inf }}$ area under the drug plasma concentration-time curve from time 0 to infinity, INS- $\mathrm{C}_{\max }$ maximum insulin aspart concentration in plasma. 
with CVs of $10.01 \%$ (90\% CI: 8.65-11.93) for INS-AUC ${ }_{i n f}$ and $17.56 \%$ (15.19-20.90) for INS-C $\mathrm{C}_{\max }$.

\section{Pharmacodynamics}

The pharmacodynamic profiles of the three insulin aspart products were similar, as shown in plots of the median of percentage of cumulative glucose infusion based on GIR$\mathrm{AUC}_{0-12 \mathrm{~h}}$ versus time (Fig. 1C) and the mean smoothed bodyweight-standardized GIR and BG control versus time (Fig. 1D). The overall pharmacodynamic effects of the three insulin aspart products were generally similar, displaying a short time-action profile.

The extent of glucose-lowering effect, as indicated by GIR-AUC ${ }_{0-12 \mathrm{~h}}$ and $\mathrm{GIR}_{\max }$, was similar among the three treatments (Table 3), with the $90 \%$ CIs and even the $95 \%$ CIs for the pairwise treatment ratio entirely within the predefined interval of 0.80 to 1.25 , thereby demonstrating equipotency of SAR-Asp, NN-Asp-US, and NN-Asp-EU. Descriptive statistics per treatment for pharmacodynamic parameters are shown in Supplementary Table S1. Between-subject variability for GIR-AUC ${ }_{0-12 \mathrm{~h}}$ and $\mathrm{GIR}_{\max }$ was low, as demonstrated by CVs per treatment between $18 \%$ and $27 \%$. Within-subject variability across the three clamps was low, with CVs of $17.12 \%$ (90\% CI: 14.81-20.38) for GIR-AUC ${ }_{0-12 h}$ and $15.48 \%(13.39-18.42)$ for GIR $_{\max }$. Consistent with the GIR, the mean smoothed BG profiles were similar for all three insulin aspart formulations (Fig. 1D).

The clamp was stopped prematurely, due to BG levels having reached the predefined criteria threshold $(\geq 200 \mathrm{mg} / \mathrm{dL}$ for $30 \mathrm{~min}$ ) in 17,18 , and 15 subjects after administration of SAR-Asp, NN-Asp-US, and NN-Asp-EU, respectively. The mean end duration of euglycemia was 7.09, 7.24, and 7.24 h after dosing for SAR-Asp solution, NN-Asp-US, and NNAsp-EU, respectively (Table 4).

Table 3. Pharmacodynamic EndPoints

\begin{tabular}{|c|c|c|c|}
\hline Endpoint & Treatment ratio & $\begin{array}{l}\text { Point estimate } \\
(90 \% C I)^{\mathrm{a}}\end{array}$ & $(95 \% C I)^{\mathrm{a}}$ \\
\hline \multicolumn{4}{|c|}{ GIR-AUC ${ }_{0-12 \mathrm{~h}}$} \\
\hline & $\begin{array}{l}\text { SAR-Asp vs. } \\
\text { NN-Asp-EU }\end{array}$ & $0.96(0.89-1.04)$ & $(0.88-1.05)$ \\
\hline & $\begin{array}{l}\text { SAR-Asp vs. } \\
\text { NN-Asp-US }\end{array}$ & $0.99(0.91-1.07)$ & $(0.90-1.08)$ \\
\hline & $\begin{array}{c}\text { NN-Asp-US vs. } \\
\text { NN-Asp-EU }\end{array}$ & $0.97(0.90-1.05)$ & $(0.89-1.07)$ \\
\hline \multirow{4}{*}{$\mathrm{GIR}_{\max }{ }^{\mathrm{b}}$} & & & \\
\hline & $\begin{array}{l}\text { SAR-Asp vs. } \\
\text { NN-Asp-EU }\end{array}$ & $1.02(0.95-1.09)$ & $(0.94-1.10)$ \\
\hline & $\begin{array}{l}\text { SAR-Asp vs. } \\
\text { NN-Asp-US }\end{array}$ & $1.03(0.96-1.10)$ & $(0.95-1.12)$ \\
\hline & $\begin{array}{c}\text { NN-Asp-US vs. } \\
\text { NN-Asp-EU }\end{array}$ & $0.99(0.92-1.06)$ & $(0.91-1.07)$ \\
\hline
\end{tabular}

${ }^{\mathrm{a}} 90 \%$ and $95 \%$ CI for the pairwise treatment ratios.

${ }^{\mathrm{b}} \mathrm{GIR}_{\max }$ is based on smoothed GIR profiles (LOESS method, tension 0.06).

GIR, body weight standardized glucose infusion rate; GIR$\mathrm{AUC}_{0-12 \mathrm{~h}}$, area under the body weight-standardized GIR rate versus time curve from 0 to 12 hours; GIR $_{\max }$, maximum smoothed body weight standardized GIR; LOESS, locally weighted regression in smoothing scatter plots.
Clamp quality was assessed using several recommended parameters (Table 4). Individual mean BG during euglycemia showed mean values of $100.06,100.59,100.10 \mathrm{mg} / \mathrm{dL}$ for SAR-Asp, NN-Asp-US, and NN-Asp-EU, respectively. The individual $\mathrm{CV} \%$ of $\mathrm{BG}$ measurements during euglycemia showed median values of $6.60 \%, 6.40 \%$, and $5.75 \%$ for SARAsp, NN-Asp-US, and NN-Asp-EU, respectively. Similarly, the mean absolute difference between individual mean $\mathrm{BG}$ measurements and the BG target level was $0.47 \mathrm{mg} / \mathrm{dL}$ for SAR-Asp, $1.14 \mathrm{mg} / \mathrm{dL}$ for NN-Asp-US, and $0.53 \mathrm{mg} / \mathrm{dL}$ for NN-Asp-EU.

\section{Safety and tolerability}

Single doses of the three insulin aspart products were well tolerated, with few AEs. Treatment-emergent adverse events (TEAEs) were reported in 3 of 29 subjects following administration of SAR-Asp, in 1 of 30 subjects following administration of NN-Asp-US, and in 4 of 30 subjects following administration of NN-Asp-EU. The most commonly reported TEAE was vomiting, reported by three subjects (one subject each following administration of SAR-Asp, NN-Asp-US, and $\mathrm{NN}-\mathrm{Asp}$-EU). There was one TEAE of severe intensity (joint dislocation while playing sport 1 day after administration of NN-Asp-EU), no deaths, and no subject experienced a TEAE that led to study discontinuation. All AEs were resolved by the end of the trial. One injection site reaction TEAE (erythema at injection site) was reported following administration of SAR-Asp. The event was rated as mild in intensity and resolved spontaneously.

\section{Discussion}

In this single-dose crossover study in subjects with T1D, SAR-Asp insulin aspart solution for injection demonstrated similar pharmacokinetic exposure and glucodynamic activity to commercially available insulin aspart formulations, as assessed by the euglycemia clamp technique.

The design of this study, using a single-dose crossover design and a euglycemic clamp procedure, is consistent with regulatory guidance for the development of biosimilar insulins. ${ }^{8}$ A similar design was used for a study, in which similar insulin exposure and pharmacodynamic activity was demonstrated for the rapid-acting insulin lispro biosimilar/ follow-on product SAR342434 compared with its US-and EU-approved marked products. ${ }^{12}$ Exposure was assessed from insulin concentration-time profiles while insulin activity was assessed as glucose utilization in a euglycemic clamp setting. The crossover design allowed each subject to receive all three treatments, so that a comparison among the three treatments could be made on the same subject. The Williams design, ${ }^{15}$ which consists of three treatments and three periods $(3 \times 3)$ in six sequences, is an ideal choice when there are three treatments in a bioequivalence study, especially given the short half-life of the insulins tested in this study that allowed complete washout between drug administration in the three treatment periods. Consistent with previous clamp studies evaluating prandial insulins, ${ }^{12,16}$ the study was conducted without the use of a basal insulin to assess the biosimilarity among SAR-Asp, NN-Asp-US, and NN-Asp-EU without confounding additional insulin exposure from basal insulin products. Standardization of clamp technique and factors influencing insulin sensitivity such as time of day, 
Table 4. Performance of Clamp During Euglycemia ${ }^{a}$

\begin{tabular}{|c|c|c|c|}
\hline Parameter and unit & $S A R-A s p(\mathrm{n}=29)$ & $N N-A s p-U S(\mathrm{n}=29)$ & $N N-A s p-E U(\mathrm{n}=30)$ \\
\hline \multicolumn{4}{|c|}{ Duration of euglycemia (hours) ${ }^{a}$} \\
\hline Mean \pm SD & $7.09 \pm 2.16$ & $7.24 \pm 1.97$ & $7.24 \pm 1.62$ \\
\hline Median (range) & $6.50(4.0-12.0)$ & $6.97(2.9-12.0)$ & $6.74(4.7-11.0)$ \\
\hline \multicolumn{4}{|c|}{ Individual mean of $B G$ concentration (during euglycemia) $(\mathrm{mg} / \mathrm{dL})^{\mathrm{a}}$} \\
\hline Mean \pm SD & $100.06 \pm 0.69$ & $100.59 \pm 1.74$ & $100.10 \pm 0.68$ \\
\hline Median (range) & $100.10(97.6-101.3)$ & $100.20(98.4-107.7)$ & $100.30(98.5-101.8)$ \\
\hline \multicolumn{4}{|c|}{ Individual CV\% of BG (during euglycemia) $(\%)^{\mathrm{a}}$} \\
\hline Mean \pm SD & $6.57 \pm 1.24$ & $6.76 \pm 1.63$ & $6.43 \pm 1.94$ \\
\hline Median (range) & $6.60(4.6-9.2)$ & $6.40(4.4-11.6)$ & $5.75(3.6-11.3)$ \\
\hline \multicolumn{4}{|c|}{ Absolute deviation of individual mean BG from clamp level (during euglycemia) $(\mathrm{mg} / \mathrm{dL})^{\mathrm{a}}$} \\
\hline Mean \pm SD & $0.47 \pm 0.51$ & $1.14 \pm 1.43$ & $0.53 \pm 0.43$ \\
\hline Median (range) & $0.30(0.0-2.4)$ & $0.90(0.0-7.7)$ & $0.40(0.0-1.8)$ \\
\hline
\end{tabular}

${ }^{a}$ Euglycemia starts with dosing and ends with the last value of the smoothed BG concentration curve $\leq 105 \mathrm{mg} / \mathrm{dL}[5.8 \mathrm{mmol} / \mathrm{L}]$. Clamp level (BG target) was $100 \mathrm{mg} / \mathrm{dL}$ [5.5 mmol/L].

$\mathrm{BG}$, blood glucose; $\mathrm{CV}$, coefficient of variation.

physical activity, food intake/diet, avoidance of alcohol, caffeinated drinks, smoking, or medication other than the study medication are all important factors to be considered in undertaking a successful clamp study. ${ }^{8}$

The $0.3 \mathrm{U} / \mathrm{kg}$ dose of SAR-Asp and commercially available insulin aspart formulations used in the study permitted effective pharmacokinetic and pharmacodynamic characterization and comparison; this dose is well characterized to provide strong effects in the euglycemic clamp (i.e., glucose demand reflected in a sizable GIR up to $12 \mathrm{~h}$ ) in subjects with $\mathrm{T} 1 \mathrm{D},{ }^{17,18}$ is recommended in current guidelines for the development of biosimilar insulins, ${ }^{8}$ and is consistent with prior insulin aspart clamp studies. ${ }^{17,18}$

Consistent with current guidelines, ${ }^{14}$ the quality of the clamp performance was measured by several parameters, including the duration of euglycemia, the individual mean of BG concentration, clamp precision (BG fluctuation from the clamp), and the control deviation (mean difference of individual mean BG measurements from the target clamp level). Individual mean BG during euglycemia had mean values between 100.06 and $100.59 \mathrm{mg} / \mathrm{dL}$, indicating that the BG was controlled with very small mean deviation from the target clamp level of $100 \mathrm{mg} / \mathrm{dL}$. In addition, clamp precision, as reflected by the median $\mathrm{CV} \%$ of individual $\mathrm{BG}$ measurements during euglycemia, ranged from $5.75 \%$ to $6.60 \%$, indicating low BG fluctuation and precise BG control at the clamp target level. This was supported by the low mean absolute difference between the individual mean BG and the target BG level between 0.47 and $1.14 \mathrm{mg} / \mathrm{dL}$, showing that the control at the clamp target level was also well achieved on an individual basis. These findings are indicative of successful performance of the euglycemic clamp technique with $\mathrm{BG}$ control close to the clamp target throughout the study ${ }^{14}$ Overall clamp quality was consistent with findings observed in previous studies. ${ }^{12}$ The withinsubject variability of exposure and activity across the three clamps was low, indicating high day-to-day reproducibility, and is comparable to data from other rapid-acting insulin analogs. ${ }^{12,19-21}$

Strengths of the current study include its crossover design using single subcutaneous doses that enables the subjects to act as their own control, along with enrolment of subjects with T1D that allows comparison of exogenous insulins with respect to glucose-lowering effect without interference from endogenous insulin. ${ }^{22}$ Investigator related bias was avoided by the automated glucose clamp procedure and the use of a double-blind design. An inherent limitation of the euglycemic glucose clamp technique to assess the pharmacodynamic properties is the requirement for standardized and well-controlled conditions (e.g, a long fasting period, washout of current insulin, absence of basal insulin, and administration of a fixed dose). In this regard, the set-up and performance of the clamp technique is aimed at optimizing the sensitivity for identifying potential differences between the investigated insulins rather than at establishing real-life conditions. ${ }^{13}$ Another potential limitation was that the study population only included males. Restriction of studies to males alone is considered acceptable, as insulin sensitivity in women may vary during the menstrual cycle. ${ }^{8}$

\section{Conclusion}

In summary, SAR-Asp demonstrated similar pharmacokinetic exposure and glucodynamic activity to commercially available insulin aspart formulations, supporting further clinical evaluation of SAR-Asp as a biosimilar/follow-on product.

\section{Acknowledgments}

We thank Xavier Benain, Anne Lehmann, Peter Bunning, Baerbel Rotthaeuser, Reinhard Becker, and Irma Slomp, all employed by Sanofi, for their assistance during the conduct and analysis of this study.

\section{Author Disclosure Statement}

C.K. is an employee and co-owner of Profil which has received research funds from ADOCIA, Biocon, Boehringer Ingelheim Pharmaceuticals, Inc., Dance Biopharm Holdings, Inc., Eli Lilly and Company, Gan \& Lee Pharmaceuticals, MedImmune, Mylan, Nordic Bioscience, Nestlé, Novo Nordisk A/S, Poxel SA, Sanofi-Aventis, Wockhardt, Xeris Pharmaceuticals, Inc., Zealand Pharma A/S. L.N. is an employee of Profil Neuss. W.S., L.T. and I.N. are employees of Sanofi. 


\section{Funding Information}

This study was funded by Sanofi. The funder participated in trial design, data collection, and analysis.

\section{Supplementary Material}

Supplementary Table S1

Supplementary Figure S1

Supplementary Figure S2

\section{References}

1. NovoLog, Insulin Aspart Injection 100 units/mL, Novo Nordisk. Prescribing information, revised: 11/2019. https:// www.novo-pi.com/novolog.pdf (accessed November 30, 2019).

2. European Medicines Agency: NovoRapid. Summary of Product Characteristics, 23 August 2019. https://www.ema .europa.eu/en/documents/product-information/novorapidepar-product-information_en.pdf (accessed September 1, 2019).

3. Hermansen K, Bohl M, Schioldan AG: Insulin aspart in the management of diabetes mellitus: 15 years of clinical experience. Drugs 2016;76:41-74.

4. Cefalu WT, Dawes DE, Gavlak G, et al.: Insulin access and affordability working group. Insulin access and affordability working group: conclusions and recommendations. Diabetes Care 2018;41:1299-1311.

5. Rotenstein LS, Ran N, Shivers JP, et al.: Opportunities and challenges for biosimilars: what's on the horizon in the global insulin market? Clin Diabetes 2012;30:138-150.

6. European Medicines Agency: Insulin Lispro Sanofi: Summary of Product Characteristics, version 17 June 2019. https:// www.ema.europa.eu/en/documents/product-information/ insulin-lispro-sanofi-epar-product-information_en.pdf (accessed July 23, 2019).

7. U.S. Food and Drug Administration: FDA Approves Admelog, the First Short-Acting "follow-on" Insulin Product to Treat Diabetes [News Release], 11 December 2017. https://www.fda.gov/news-events/press-announcements/fdaapproves-admelog-first-short-acting-follow-insulin-producttreat-diabetes (accessed May 15, 2019).

8. European Medicines Agency: Guideline on Non-clinical and Clinical Development of Similar Biological Medicinal Products Containing Recombinant Human Insulin and Insulin Analogues, 26 February 2015. https://www.ema .europa.eu/en/documents/scientific-guideline/guideline-nonclinical-clinical-development-similar-biological-medicinalproducts-containing_en-0.pdf (accessed July 23, 2019).

9. U.S. Food and Drug Administration, Center for Drug Evaluation and Research (CDER): Guidance for Industry: Scientific Considerations in Demonstrating Biosimilarity to a Reference Product. April 2015:1-24. https://www.fda .gov/media/82647/download (accessed July 23, 2019).

10. U.S. Food and Drug Administration, Center for Drug Evaluation and Research (CDER): Guidance for Industry: Questions and Answers on Biosimilar Development and the
BPCI Act (Revision 1), December 2018:1-19. https://www .fda.gov/media/119258/download (accessed July 23, 2019).

11. U.S. Food and Drug Administration, Center for Drug Evaluation and Research (CDER): Guidance for Industry. New and Revised Draft Q\&As on Biosimilar Development and the BPCI Act (Revision 2) (Draft Guidance), December 2018:1-14. https://www.fda.gov/media/119278/download (accessed July 23, 2019).

12. Kapitza C, Nowotny I, Lehmann A, et al.: Similar pharmacokinetics and pharmacodynamics of rapid-acting insulin lispro products SAR342434 and US- and EU-approved Humalog in subjects with type 1 diabetes. Diabetes Obes Metab 2017;19:622-627.

13. Heise T, Zijlstra E, Nosek L, et al.: Euglycaemic glucose clamp: what it can and cannot do, and how to do it. Diabetes Obes Metab 2016;18:962-972.

14. Benesch $\mathrm{C}$, Heise $\mathrm{T}$, Klein $\mathrm{O}$, et al: How to assess the quality of glucose clamps? Evaluation of clamps performed with ClampArt, a novel automated clamp device. J Diabetes Sci Technol 2015;9:792-800.

15. Williams EJ: Experimental designs balanced for the estimation of residual effects of treatments. Aust J Chem 1949; 2:149-168.

16. Heise T, Hovelmann U, Brondsted L, et al.: Faster-acting insulin aspart: earlier onset of appearance and greater early pharmacokinetic and pharmacodynamic effects than insulin aspart. Diabetes Obes Metab 2015;17:682-688.

17. Heise T, Eckers U, Kanc K, et al.: The pharmacokinetic and pharmacodynamic properties of different formulations of biphasic insulin aspart: a randomized, glucose clamp, crossover study. Diabetes Technol Ther 2008;10:479-485.

18. Nosek L, Roggen K, Heinemann L, et al.: Insulin aspart has a shorter duration of action than human insulin over a wide dose-range. Diabetes Obes Metab 2013;15:77-83.

19. Heinemann L, Weyer C, Rauhaus M, et al.: Variability of the metabolic effect of soluble insulin and the rapid-acting insulin analog insulin aspart. Diabetes Care 1998;21:19101914.

20. de la Peña A, Seger M, Soon D, et al.: Bioequivalence and comparative pharmacodynamics of insulin lispro $200 \mathrm{U} / \mathrm{mL}$ relative to insulin lispro (Humalog ${ }^{\circledR}$ ) $100 \mathrm{U} / \mathrm{mL}$. Clin Pharmacol Drug Dev 2016;5:69-75.

21. Becker RH, Frick AD: Clinical pharmacokinetics and pharmacodynamics of insulin glulisine. Clin Pharmacokinet 2008;47:7-20.

22. Swinnen SG, Holleman F, DeVries JH: The interpretation of glucose clamp studies of long-acting insulin analogues: from physiology to marketing and back. Diabetologia 2008; 51:1790-1795.

Address correspondence to: Christoph Kapitza, $M D$

Profil Institut für Stoffwechselforschung $\mathrm{GmbH}$ Hellersbergstraße 9 Neuss D-41460 Germany

E-mail: christoph.kapitza@profil.com 